\title{
Communicating Findings of Delayed Diagnostic Evaluation to Primary Care Providers
}

\author{
Ashley N. D. Meyer, PhD, Daniel R. Murphy, MD, and Hardeep Singh, MD
}

Background: We previously found that an intervention involving electronic algorithms to detect delays in follow-up of cancer-related abnormal or "red-flag" findings and communicating this information to primary care providers (PCPs) led to more timely diagnostic evaluation. In this study, we examined the effectiveness of various communication strategies to inform PCPs about the delayed follow-up.

Methods: After identifying follow-up delays through electronic health record-based algorithms and record reviews, we communicated this information to PCPs using 3 escalating steps. First, we sent secure E-mails. If no evidence of follow-up was found in a medical record review after 1 week, we made up to 3 attempts to reach the PCPs or their nurses via telephone. If they could not be reached, we informed clinic directors as the third and final step. In this analysis, we evaluate PCPs' follow-up in response to these methods of communication.

Results: A total of 733 patients with follow-up delays were identified (369 patients in the intervention group and 364 patients in the control group). Communicating information to PCPs about possible follow-up delays led to decreased times to diagnostic evaluation, but communication related to delays did not always lead to follow-up for the patients in the intervention group. Specifically, secure E-mails led to follow-up in 11.1\% of cases (41 of 369), telephone calls led to follow-up in 68.6\% of cases (225 of 328), and contacting clinic directors led to follow-up in $\mathbf{5}$ of $\mathbf{1 1}$ cases in which communication escalated to this level.

Conclusion: Strategies to communicate to PCPs information on delayed follow-up of findings suspicious for cancer were useful, but not fail-safe. Additional back-up strategies, such as using case coordinators, might be needed. (J Am Board Fam Med 2016;29:469-473.)

Keywords: Algorithms, Ambulatory Care Facilities, Communication, Control Groups, Electronic Health Records, Electronic Mail, Follow-Up Studies, Humans, Neoplasms, Primary Care Providers, Telephone

Failure to follow-up abnormal or "red-flag" clinical findings (test results, signs, and symptoms) can lead to delays in diagnostic evaluation and poor clinical

\footnotetext{
This article was externally peer reviewed.

Submitted 23 November 2015; revised 28 March 2016; accepted 18 April 2016.

From the Houston Veterans Affairs Center for Innovations in Quality, Effectiveness and Safety, Michael E. DeBakey Veterans Affairs Medical Center, Houston, TX; and the Section of Health Services Research, Department of Medicine, Baylor College of Medicine, Houston.

Funding: This work was supported by the Agency for Health Care Research and Quality (grant no. R18HS017820) and the Houston Veterans Affairs Health Services Research \& Development Center for Innovations in Quality, Effectiveness and Safety (CIN 13-413). DRM is supported by a Mentored Career Development Award (grant K08HS022901) from the Agency for Healthcare Research and Quality. HS is also supported by the VA Health Services Research and Development Service (CRE 12-033; Presidential Early Career Award for Scientists and Engineers USA 14274), the VA National Center for Patient Safety, and the
}

outcomes. ${ }^{1-4}$ To our knowledge, no studies have explored how to effectively communicate information about these delays, once identified, to frontline providers in near real time.

In a recent randomized control trial (RCT), we found that an intervention using electronic algorithms to find delays in follow-up of cancer-related "red-flag" findings and communicating this information to primary care providers (PCPs) led to

Agency for Health Care Research and Quality (grant R01HS022087).

Conflict of interest: none declared.

Disclaimer: The views expressed in this article are those of the authors and do not necessarily represent the views of the Department of Veterans Affairs or any other funding agency.

Corresponding author: Ashley Meyer, $\mathrm{PhD}$, Center for Innovations in Quality, Effectiveness and Safety (152) 2002 Holcombe Boulevard, Houston, TX 77030 (E-mail: ameyer@bcm.edu). 
more timely diagnostic evaluation. ${ }^{5}$ The communication strategy involved escalating steps, progressing from sending secure E-mails to making telephone calls to informing clinic directors if phone calls did not result in successful contact. In this analysis, we examine the effectiveness of these communication strategies to understand each method's effect on PCP responsiveness to communication. The knowledge gained could inform future interventions to prompt provider follow-up when such follow-up is needed.

\section{Methods \\ Participants}

In the RCT, 72 PCPs (physicians, physician assistants, and nurse practitioners) from 2 sites (a large, urban Veterans Affairs facility and a private health system) were recruited and randomly assigned to each of the control (usual care) and intervention groups in equal number. Electronic algorithms designed to identify patients with potential delays in diagnostic evaluation for lung, colorectal, or prostate cancer were applied to the electronic health records (EHRs) of all patients seen by these PCPs from April 20, 2011, to July 19, 2012 (approximately 118,400 unique patients). Algorithms included "red-flag" findings to identify patients with possible cancer, clinical exclusion criteria to eliminate patients for whom further evaluation was not warranted, and expected follow-up criteria to eliminate patients who already had follow-up (see Table 1; additional details are described elsewhere ${ }^{2,5,6}$ ). The electronic algorithms identified 1,256 patients with possible delays in diagnostic evaluation. Manual chart review (which was done to verify that follow-up was not missed by the algorithm) indicated that 749 indeed needed follow-up. Excluding 16 patients whose providers left during the intervention, this left 733 patients (364 patients in the control group and 369 patients in the intervention group). The intervention group of 369 patients is the focus of this additional analysis. Institutional review boards at both sites approved the study, with waivers for patient consent. Written consent was obtained from providers upon enrollment in the study.

\section{Procedure}

Upon recruitment for the RCT, PCPs specified communication preferences, including preferred $\mathrm{E}$ - mail addresses/telephone numbers, times of day to call, and whether telephone calls should be made to PCPs or their nurses. After confirming delays, we communicated the information to PCPs via secure E-mail. This communication included the patient's name, medical record number, test name, and test date. The goal of the communication was to convey that a patient might be experiencing a delay in follow-up for a diagnostic evaluation. If the PCP did not follow-up within 1 week, we made up to 3 telephone calls containing the same information that was conveyed in the secure E-mail to PCPs or their nurses. Follow-up was defined as following through with appropriate diagnostic evaluation or documenting intentionally delayed follow-up (eg, documenting watchful waiting of elevated prostatespecific antigen). Lastly, if no one could be reached, we informed clinic directors. Final patient outcomes regarding follow-up and the presence of cancer were assessed by chart review 7 months after the initial "red-flag" findings.

\section{Analyses}

In this analysis, we descriptively examined PCP follow-up to each communication method for the 369 cases of delayed diagnostic evaluation in the intervention group. In addition, $\chi^{2}$ analyses compared follow-up resulting from contact with a PCP versus a nurse for telephone calls and for each communication method by site.

\section{Results}

\section{Brief Summary of the RCT}

For the 733 patients identified as having delays in diagnostic evaluation in the RCT, times to diagnostic evaluation were significantly shorter for patients in the intervention group than they were for patients in the control group identified by the colorectal cancer algorithm (median, 104 vs 200 days, respectively; $\mathrm{n}=557 ; P<.001)$ and the prostate cancer algorithm (40\% received evaluation at 144 vs 192 days, respectively; $\mathrm{n}=157 ; P<.001$ ), but not the lung cancer algorithm (median, 65 vs 93 days, respectively; $\mathrm{n}=19 ; P=.59) .{ }^{5}$ More intervention patients than control patients received diagnostic evaluation by final review $(73.4 \%$ vs $52.2 \%$, respectively; relative risk, 1.41 ; $95 \%$ confidence interval, 1.25-1.58). Lastly, cancer diagnoses were confirmed in 23 patients during the 7 -month follow-up period (10 in the control group and 13 in 
Table 1 "Red-Flag," Clinical Exclusion, and Expected Follow-up Criteria by Cancer Type Used in Electronic Algorithms Applied to the Electronic Health Records of 118,400 Patients from April 20, 2011, to July 19, 2012

\begin{tabular}{|c|c|c|c|}
\hline Cancer & "Red-Flag" Criteria & Clinical Exclusion Criteria & Expected Diagnostic Evaluation \\
\hline Lung cancer & $\begin{array}{l}\text { Any of the following flagged by } \\
\text { radiologist as suspicious for } \\
\text { malignancy: } \\
\text { - Chest radiograph or chest } \\
\text { CT scan }\end{array}$ & $\begin{array}{l}\text { - Age }<30 \text { years } \\
\text { - Prior history of lung cancer } \\
\text { - Terminal illness diagnosis } \\
\text { - Hospice/palliative care enrollment } \\
\text { - Prior tuberculosis diagnosis } \\
\text { - Pulmonary evaluation within last } 6 \\
\text { months }\end{array}$ & $\begin{array}{l}\text { Any of the following within } 30 \text { days } \\
\text { after red-flag criteria: } \\
\text { - Pulmonary referral completed } \\
\text { - Lung procedure (biopsy, } \\
\text { bronchoscopy, thoracic } \\
\text { surgery) } \\
\text { - Repeat x-ray or CT scan }\end{array}$ \\
\hline Colon cancer & $\begin{array}{l}\text { Positive FOBT, or } \\
\text { New hematochezia diagnosis or } \\
\text { Laboratory results consistent } \\
\text { with IDA: } \\
\text { - Hemoglobin } \leq 11 \mathrm{~g} / \mathrm{dL} \\
\text { - Mean corpuscular volume } \\
\leq 81 \mathrm{fL} \\
\text { - No ferritin } \geq 100 \mathrm{ng} / \mathrm{mL} \\
\text { in prior } 12 \text { months }\end{array}$ & $\begin{array}{l}\text { - Age }<40 \text { or }>75 \text { years } \\
\text { - Colonoscopy within } 5 \text { years (for } \\
\text { positive FOBT) or } 3 \text { years (for } \\
\text { hematochezia or IDA) prior to high- } \\
\text { risk criteria met } \\
\text { - Prior history of colorectal cancer } \\
\text { - Prior total colectomy } \\
\text { - Terminal illness diagnosis } \\
\text { - Hospice/palliative care enrollment } \\
\text { - Upper GI bleed within } 1 \text { year before } \\
\text { or } 60 \text { days after red-flag criteria are } \\
\text { met } \\
\text { Additional IDA-specific criteria include } \\
\text { the following: } \\
\text { - Prior thalassemia diagnosis } \\
\text { - Hospitalization within } 14 \text { days before } \\
\text { red-flag criteria met } \\
\text { - Surgery within } 14 \text { days before high-risk } \\
\text { criteria met } \\
\text { - Menorrhagia diagnosis within } 5 \text { years } \\
\text { before or } 60 \text { days after high-risk } \\
\text { criteria met } \\
\text { - Other cause of bleeding within } 1 \text { year } \\
\text { before or } 60 \text { days after high-risk } \\
\text { criteria met } \\
\text { - Pregnant within } 1 \text { year before or } 60 \\
\text { days after high-risk criteria met }\end{array}$ & $\begin{array}{l}\text { - Colonoscopy performed within } \\
60 \text { days after red-flag criteria }\end{array}$ \\
\hline Prostate cancer & PSA result of $4.1-15 \mathrm{ng} / \mathrm{mL}$ & $\begin{array}{l}\text { - Age }<40 \text { or }>70 \text { years } \\
\text { - Prior history of prostate cancer } \\
\text { - Prostate biopsy within prior } 2 \text { years } \\
\text { - Prostatitis diagnosis within } 30 \text { days } \\
\text { before or } 90 \text { days after red-flag criteria } \\
\text { met } \\
\text { - Terminal illness diagnosis } \\
\text { - Hospice/palliative care enrollment }\end{array}$ & $\begin{array}{l}\text { Any of the following within } 90 \text { days } \\
\text { after red-flag criteria: } \\
\text { - Repeat PSA performed } \\
\text { - Urology referral requested or } \\
\text { completed } \\
\text { - Prostate biopsy performed }\end{array}$ \\
\hline
\end{tabular}

CT, computed tomography; FOBT, fecal occult blood test; GI, gastrointestinal; IDA, iron-deficiency anemia; PSA, prostate-specific antigen. Reprinted with permission. (C) (2015) American Society of Clinical Oncology. All rights reserved. Murphy et al: J Clin Oncol 33(31), 2015: 3560-7.5

the intervention group; $P=.66$ ). Additional results have been described previously. ${ }^{5}$

\section{Follow-up Resulting from Intervention Communication}

Communicating information to PCPs about possible delays in diagnostic evaluation did not always result in follow-up (see Figure 1). Specifically, secure E-mails led to follow-up in $11.1 \%$ of cases (41 of 369). Telephone calls led to follow-up in $68.6 \%$ of cases where this escalation occurred (225 of 328) or in $71.0 \%$ of cases in which a provider could be reached (225 of 317). Lastly, contacting clinic directors led to follow-up in 5 of the 11 cases where communication escalated to the highest level. $\mathrm{Cu}-$ mulatively, this led to $11.1 \%, 72.1 \%$, and $73.4 \%$ response rates for the various communication attempts. Whether PCPs or nurses were the designated telephone call recipients made no difference in resultant follow-up $(P=.82)$ : calling PCPs led to follow-up in $67.9 \%$ of cases (133 of 223) and calling nurses led to follow-up in $69.7 \%$ of cases (92 of 146). However, PCPs at the Veterans Affairs facility followed up in response to $73.6 \%$ of telephone 
Figure 1. Diagram of primary care provider (PCP) follow-up by type of communication. Percentages total 100 at each branching point.

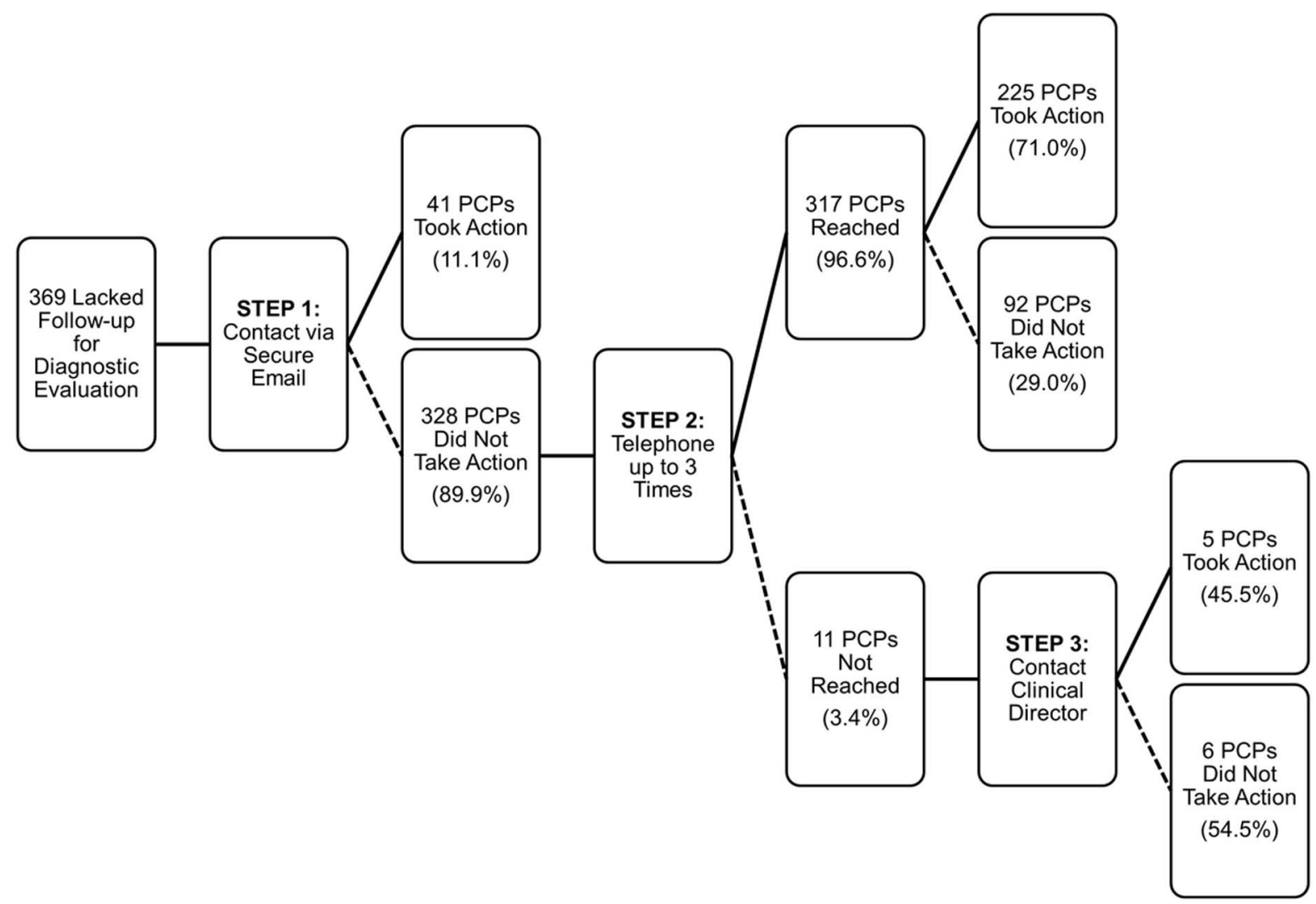

calls (204 of 277), whereas PCPs at the private health system followed up in response to fewer calls $(52.5 \% ; 21$ of $40 ; P=.006)$. Follow-up after secure E-mails, however, was comparable across sites: PCPs at the Veterans Affairs facility followed up in response to $11.4 \%$ of E-mails (37 of 324) and PCPs at the private health system followed up in response to $8.9 \%$ of E-mails ( 4 of $45 ; P=.61$ ).

\section{Discussion}

With increasing EHR adoption, it is essential to leverage the wealth of EHR data and bring it to the point of care to improve health care quality. However, communicating information to PCPs about possible delays in diagnostic evaluation has not been studied thus far and it must fit within PCPs' workflow to be effective. We found that secure E-mails lead to follow-up actions in only a small percentage of cases, and additional strategies such as telephone calls and contacting clinic directors had only moderate effects on follow-up. Given the relatively modest effect of these strategies for com- municating diagnostic delays, the potential of such interventions is likely to be significantly dampened. Our findings highlight the complexity of communicating important information to providers to improve patient care in near real time.

We also found that delivering the information to nurses was as effective as delivering it directly to PCPs, suggesting that team-based approaches to communication may be feasible and may avoid contributing to the "information overload" PCPs already experience. ${ }^{7-10}$ With increasing use of EHRs by PCPs to provide care, ${ }^{11}$ electronic data capturing clinical practice and quality of care have proliferated, allowing interventions that leverage these data to be developed and used to improve patient care at the point of care. ${ }^{12,13}$ However, implementation of such interventions faces many challenges, such as the need for resources to develop and implement algorithms to extract EHR data and administrative or clinical personnel to deliver it to the point of care. ${ }^{6}$ Additional research is needed to ensure such interventions are trans- 
lated successfully into practice. ${ }^{14}$ Back-up strategies using organizational mechanisms (such as case coordinators) could also be considered to support PCPs in tracking and follow-up.

There are several limitations to this study. While communicated information was not always acted on, we did not obtain direct feedback from PCPs as to why. Thus, we were unable to determine reasons for delays in follow-up despite being notified (unless documented in the medical record). Future qualitative research on this topic should investigate these reasons in detail to help develop better implementation strategies. In addition, the work was not designed to test improvements in health outcomes, which would require much longer follow-up of patients and a much larger sample. Despite these limitations, this is the first examination of methods to communicate potential delays in diagnostic evaluation to frontline providers. Understanding the impact of communicating information to minimize care delays, however, is an important step in ultimately getting patients better care and improving health outcomes.

\section{Conclusion}

To leverage the wealth of EHR data and bring it to the point of care to improve health care quality, more robust strategies for communicating information on follow-up delays are needed. Future research in primary care should focus on how to ensure these strategies fit within the workflow of PCPs. In addition, back-up strategies using organizational mechanisms (such as case coordinators) could also be considered to support PCPs in tracking and follow-up.

The authors acknowledge Louis Wu, Eric J. Thomas, and Samuel N. Forjuoh, who played critical roles in the primary study that this report came from. Without their help on the initial study, this additional analysis would not have been possible.

\section{References}

1. Gandhi TK, Kachalia A, Thomas EJ, et al. Missed and delayed diagnoses in the ambulatory setting: a study of closed malpractice claims. Ann Intern Med 2006;145:488-96.
2. Murphy DR, Laxmisan A, Reis BA, et al. Electronic health record-based triggers to detect potential delays in cancer diagnosis. BMJ Qual Saf 2014;23:8-16.

3. Torring ML, Frydenberg M, Hansen RP, Olesen F, Vedsted P. Evidence of increasing mortality with longer diagnostic intervals for five common cancers: a cohort study in primary care. Eur J Cancer 2013; 49:2187-98.

4. Wahls T. Diagnostic errors and abnormal diagnostic tests lost to follow-up: a source of needless waste and delay to treatment. J Ambul Care Manage 2007;30: $338-43$.

5. Murphy DR, Wu L, Thomas EJ, Forjuoh SN, Meyer AN, Singh H. Electronic trigger-based intervention to reduce delays in diagnostic evaluation for cancer: a cluster randomized controlled trial. J Clin Oncol 2015;33:3560-7.

6. Murphy DR, Thomas EJ, Meyer AN, Singh H. Development and validation of electronic health recordbased triggers to detect delays in follow-up of abnormal lung imaging findings. Radiology 2015;277:81-7.

7. Fava GA, Guidi J. Information overload, the patient and the clinician. Psychother Psychosom 2007;76: $1-3$.

8. Singh H, Spitzmueller C, Petersen NJ, Sawhney MK, Sittig DF. Information overload and missed test results in electronic health record-based settings. JAMA Intern Med 2013;173:702-4.

9. Woods DD, Patterson E, Roth EM. Can we ever escape from data overload? A cognitive systems diagnosis. Cogn Technol Work 2002;4:22-36.

10. Murphy DR, Meyer AND, Russo E, Sittig DF, Wei L, Singh H. The burden of inbox notifications in commercial electronic health records. JAMA Intern Med 2016;176:559-60.

11. Jha AK, Ferris TG, Donelan K, et al. How common are electronic health records in the United States? A summary of the evidence. Health Aff (Millwood) 2006;25:w496-w507.

12. Sittig DF, Singh H. Electronic health records and national patient-safety goals. N Engl J Med 2012; 367:1854-60.

13. Mamblin BW, Tierney WM. The promise of information and communication technology in healthcare: extracting value from the chaos. Am J Med Sci 2016;351:59-68.

14. Grol R, Grimshaw J. From best evidence to best practice: effective implementation of change in patients' care. Lancet 2003;362:1225-30. 